\title{
Exploration of nurses' perception about professionalism in home care nursing in Iran: a qualitative study
}

\author{
Naser Lotfi Fatemi ${ }^{1}$, Hossein Karimi Moonaghi ${ }^{2}$, Abbas Heydari ${ }^{2}$
}

${ }^{1}$ Ph.D. Candidate in Nursing, Department of Medical-Surgical Nursing, School of Nursing and Midwifery, Mashhad University of Medical Sciences, Mashhad, Iran

${ }^{2}$ Ph.D. of Nursing, Professor, Department of Medical-Surgical Nursing, School of Nursing and Midwifery, Mashhad University of Medical Sciences, Mashhad, Iran

\section{Type of article: Original}

\begin{abstract}
Background: Professionalism is one of the basic concepts of home care nursing, as a growing model of community-based nursing. This phenomenon results from the nurse-patient interaction in home and community environments with multiple dimensions.

Objective: The purpose of this study was to explore the professional experiences of home care nurses in Iran.

Methods: In this study, the qualitative content analysis method was used based on the 2004 Graneheim \& Lundman approach. The study was conducted between September 2016 and September 2017 in Khorasan Razavi province, Iran. Participants were selected by Purposeful Sampling. The main method of data collection was semistructured interviews with 21 nurses who had home-based care experience. Eventually, after reaching saturation, the data were analyzed in-depth.

Results: In total, 3 main categories and 11 subcategories were extracted. Generally, nurses considered the concept of professionalism in home care nursing by attention to basic values, social capital, and maintaining quality and standards of care.

Conclusion: Professionalism in home care nursing is one of today's challenges in the health system of the country, and professionalism requires more attention and conditions for its prosperity.

Keywords: Professionalism, Home care, Iran nursing, Nurses' experiences
\end{abstract}

\section{Introduction}

Professionalism is one of the challenging issues and basic concepts in nursing that results from individualenvironment interaction and interpersonal communication. Professionalism in nursing plays an important role in meeting the goals of the health system (1). It is also important to have professional and value-based foundations around it. For this reason, it is one of the concerns of health systems worldwide (2). Society, in return for giving the right to provide health services to members of the nursing profession, expects this group to provide community benefits to all its goals and ensure the quality of services by training and supervising the professionalism of its members. Therefore, members of the nursing profession are committed to making decisions and actions in the health of the patients and prefer the benefits of the patient to their own benefit. Professional nursing should be available in all aspects of care (3). In fact, being professional, is the process of obtaining specialized knowledge, skills, attitudes, values, norms and behaviors required to play a role in a profession. In other words, it is the internalization of the knowledge, skills, attitudes, behaviors, values and ethical standards of a profession and it is a part of the process of socializing the profession (4). Nowadays, we are faced with demographic changes and increasing health costs

\section{Corresponding author:}

Professor Dr. Hossein Karimi Moonaghi, Department of Medical- Surgical Nursing, School of Nursing and Midwifery, Mashhad University of Medical Sciences, Mashhad, Iran.

Tel: +98.5138591511, Fax: +98.5138597313, Email: karimih@mums.ac.ir

Received: October 24, 2017, Accepted: December 17, 2017, Published: May 2018

iThenticate screening: December 10, 2017, English editing: January 23, 2018, Quality control: March 12, 2018

This article has been reviewed / commented by five experts

Funding / research project approval: 941375

Ethics approval: IR.MUMS.REC.1395.307

(C) 2018 The Authors. This is an open access article under the terms of the Creative Commons Attribution-NonCommercialNoDerivs License, which permits use and distribution in any medium, provided the original work is properly cited, the use is non-commercial and no modifications or adaptations are made. 
worldwide. Therefore, the tendency to carry out care outside the hospital environment is increasing (5). Rapid changes in population distribution around the world towards elderly populations and increasing hospital costs have led health services to integrate into everyday life, and the care environment is changing from hospitals to homes (6). Home care nursing involves a wide range of technical and protective care for patients, post-discharge period, maintaining the health of the disabled and the elderly at home, preventing unnecessary hospitalization and meeting the daily needs of home health with the goal of rehabilitation, therapeutic and supportive care (7). Today, home care is gradually becoming an emerging industry, and becoming a common nursing model (8). Along with this change in healthcare systems, it seems a new generation of nurses have gone into professional careers (9). Experience in professionalism is one of the issues that should be given more attention to in dealing with and solving professional problems. Affecting factors on the process of nursing professionalism in home care are not just professional factors, and home nurses should adopt a more professional role in the community. Although the history of home care nursing in Iran has been long established, the recognition of the dimensions of home care nursing is a new subject and there is a significant gap in this regard. Consequently, there is not enough information available to health policy makers in Iran (10). Due to the increasing need and demand of the community for professional and committed nurses and improving the quality of services, professionalism and acts of professionalism have become key issues in health care systems. Therefore, attention to the concept of professionalization and the determination of its indicators are necessary (11). The subjective characteristics based on the quality of the unique experience for nurses, are the main challenges for understanding home care and so it is very difficult to describe it in quantitative and objective ways. How is home care in Iran? And what are the challenges in this area? These are unknown topics. This question remains unanswered. If these nurses could talk about professionalism in home care, and if they could express space, differences and challenges, opportunities and threats, what would be revealed? Therefore, the best way to answer these questions is to use the qualitative research methodology to help clarify the professionalism of home nursing care in Iran. The present study was designed and conducted to explain nurses' experiences of professionalism in home care nursing.

\section{Material and Methods}

This study was conducted to explain nurses' experiences of professional nursing in home care. Due to the multidimensional nature of professionalism, the researchers used the qualitative conventional content analysis method. The sampling was done by using purposeful and snowball sampling. Participants were selected from nurses who had at least one year of home care experience, had at least a bachelor's degree, and willingness to participate and talk about their experiences. Maximum Variance of Sampling was carried out in terms of work history and experience, and type of care such as long-term care, nursing techniques, wound care, intensive nursing care in the home, phototherapy, etc. This research was conducted between September 2016 and September 2017 in Khorasan Razavi province, Iran. In this study, 21 nurses who had the criteria for entering the study were selected, and the sampling was continued until data saturation. The main method of data collection was semi-structured interviews and the duration of each interview was between 20 and 105 minutes with an average of 48 minutes. Initially, the goals of the study were stated through telephone conversation with the nurses. After obtaining consent, the time of the interviews and the appropriate location for the participants were determined. Two of the nurses contacted refused to be interviewed. Most interviews were conducted at institutes of home nursing services, and in some cases interviewed in hospitals or nursing faculties in Mashhad. The focus of interview questions was the professional experience of nurses in home care. At first, a general question was asked, such as "Can you tell us one of your narratives of home care?" and the interview process was guided by the participants' answer. Then, exploratory and follow-up questions were asked to obtain more information and to clarify the answers of nurses. Participants were asked to provide examples to describe the subject during the interview. All the interviews were recorded and then transcribed as soon as possible. The researchers repeatedly listened to the interviews and reviewed the typed text repeatedly in order to immerse them in the data. The analysis process was carried out simultaneously with the data collection, based on the Graneheim \& Lundman approach in qualitative content analysis (12). The Inductive method and coding was used for content analysis of all interviews. In order to extract data, the text was read word by word. The words, sentences and paragraphs of the participants' statements that contained important points related to the topic were considered as Meaning Units, and text annotation with coding was done, and revealed the experiences of participating nurses. Participants' words and the researcher's perceptions were used for initial coding. The codes were refreshed several times to be placed by meaning similarity in the main categories and subcategories. Meaning units were extracted from participants' quotations in the form of initial codes. Meaning units were conceptualized, and reached the abstract level and were named in terms of their latent meaning. The codes were categorized and deformed based on the similarity and the meaning and conceptual difference, whereby the categories were made. The sweep process and the verification of all data were done separately to ensure the validity of the information 
extracted from the data. Then a more abstract conceptual name was considered for that particular category. By coding and creating relationships between each category and its associated subcategories, the data was newly linked. When there was a certain phenomenon in the data, its concepts were categorized. Finally, by redefining categories, codes and data were identified in the main body of the study. The data saturation criterion was the lack of formation of new classes among the data. At all stages, we tried to avoid the implications of the researchers' assumptions in the data analysis process. Four criteria for credibility, dependability, confirmability, and transferability were used in accordance with Lincoln and Guba to increase validity and reliability, which is equivalent to the scientific strength of the findings in qualitative research (13). Data validity increased with the maximum variance of participants' backgrounds, and diverse work experiences, and the difference in the type of home care. In order to eliminate any ambiguity in coding, credibility methods were used. The researcher compared the same concepts to their statements by member check and the degree of convergence between the extracted inputs and the experiences of the participants. We compared the degree of consistency between the extracted themes with experiences of participants. Confirmability was also possible by audit trial, recording and writing the steps and the research process accurately and with due observance of the researcher's neutrality, agreement of four home nurses on the interviews, codes and the classification of similar codes and categories. Confidence or dependability of the findings was done by writing as soon as possible, external check by using two expert colleagues in qualitative research, and revising the entire data. The rich explanation of data and transferability through interviews with different participants, providing direct quotes and examples was obtained. The researchers obtained informed consent from the participants. The informed consent form includes the right to voluntary participation in the study, the recording of anonymous interviews, the observance of confidentiality by the researcher, the ability to cancel at each stage of the investigation, the knowledge of the overall results of the study and the receipt of the audio file related to the interview of the researcher. They were also informed that, if necessary, they may be referred to again, to complete the conversation.

\section{Results}

In this study, 21 nurses (12 men and 9 women) with job experience of 2 to 28 years (average 15.5 years) and with work experience in home care between 2 and 25 years (mean 8 years) participated. The average interview time was 48 minutes. In total, three main categories of "focusing on basic values", "social capital" and "maintaining quality and standards of care" were extracted by analyzing the data. The obtained categories and subcategories in the research are indicated in Table 1.

Table 1. Overview of categories $(n=3)$ and subcategories $(n=12)$

\begin{tabular}{|l|l|}
\hline Category & Subcategory \\
\hline Attention to basic values & Compliance to law and Accountability \\
\cline { 2 - 2 } & Attention to basic values \\
\cline { 2 - 2 } & Ethically oriented \\
\hline \multirow{5}{*}{ Social capital } & Adherence to social justice \\
\cline { 2 - 2 } & Spirituality \\
\hline Maintaining quality and standards of care & Professional interaction \\
\cline { 2 - 2 } & Social position \\
\hline & Monitoring and accreditation \\
\hline & Attention to the authority of knowledge and experience \\
\hline & Specialization \\
\hline & Clinical Competency \\
\hline & Effective management \\
\hline
\end{tabular}

\subsection{Attention to basic values}

The home care nurse, as an individual, has his own values and beliefs, culture and customs. These values and beliefs may unconsciously or consciously affect their behavior, speech, and decisions. Values are one of the most important parts of professional activity. A conflict of values can change a situation or problem into an ethical challenge. One of the remarkable points in the participants' statements was their emphasis on the basic values of society and the profession, such as compliance to law and accountability, ethical orientation, adherence to social justice, and spirituality.

3.1.1. Compliance to law and Accountability

The home care nurses are responsible for their personal actions toward patients. This includes responding to provided care, maintaining patient safety, and working within the framework of assigned duties. One of the nurses 
who had 4 years of work experience at home care, said: " I told him I do not have permission to do this. I do not like to do something, only for someone to ask me later why I did this. We do not do it right now "(p.14). Another nurse said: "When a nurse works in a home care nursing setting, she is in the process of being legally accountable. .... We even try to collaborate with persons who enter home care in different ways in order to work together, legally."(p.22) 3.1.2. Ethically oriented

Understanding ethics is an important part of home care nursing. Although nursing practices in the home care setting at first glance are considered to be clinical and apart from ethics, we see a link between ethics and clinical practice. Ethics refers to the decision-making process and the practice of them, which is strongly dependent upon the work of nurses. Ethical logic in nursing is based on care and the need for interpersonal communication, and is a combination of professional values and ethical logic. Nursing values are limited to professional, personal and client factors (14). Home care nurses are constantly faced with ethical challenges. A nurse who has 25 years of work experience in home care says: "We must know that if you talk behind someone's back, they will also be talk behind your back. Every time the patients say something about my colleague, I tell the patients that my colleague is correct and my colleague has not made a mistake, and he said right. Because if today, I will talk behind my colleague, the inexperienced person will also begin to talk behind me. But when you say, that's not my colleague's purpose, and I'll fix it for you now" (p.1). Another nurse says: " Of course, the number of collaborators who speak ill of each other is very small. But these kinds of channels should be blinded, otherwise it's a bad feeling." (p6). A nurse who has 25 years of work experience tells us about ethical considerations in the patient's family: "My method is that I do not look at the patient's family members at all, especially if they are of the opposite sex. I respect the rules in the relationship, because I'm entering family privacy. This is very important to me. I do not look at her whether she has or does not have a veil." (p.1)

\subsubsection{Adherence to social justice}

"Adherence to social justice" is one of the subcategories of the main category "attention to basic values". Although nurses in the community believe that having access to health care is the right of all people in the community, they are confronted by an unbalanced distribution of wealth. A participant with 7 years of work experience at home care says: "The financial, social and cultural situation in the deprived rural areas is very bad. When a person arrives in a crowded room with an area of 9 meters, he forgets everything. The nurse is grieving for the patient and his family." (p.15). A participant with 23 years of work experience at home care nursing, says about his experience of social inequality: "Sometimes the families are so poor that the nurse is embarrassed to get paid. I sometimes go to the wealthy areas and sometimes to the poor areas of the city. God, why should all this be different? This economic difference influences me very much. It's a terrible economic gap". (p.2)

\subsubsection{Spirituality}

The strong essence of spirituality can be found in the experiences of the participants. They not only see the effectiveness of their efforts in the patients' clinical outcomes, but also believe that their own personal lives are also influenced by their efforts with the supernatural forces involved. One of the nurses says: " I feel good ... because our work has a good sense of emotional reflection. The patient prays so much that you forget about fatigue ........ " (p.14). Another participant says: "This is very important ... We live with the prayers of our patients, we must feel this and believe in it. If we do not believe it, this is an overwhelming job .... An inner feeling tells me that I live under the protection of these prayers. " (p.17). Some of them consider their presence in nursing, a divine success. A nurse says: "Thank you, God. Thank you for giving us the opportunity to reduce the pain of the patients. Thank you, God, for giving us the opportunity to have a lot of beautiful experiences." (p.21)

\subsection{Social capital}

Social capital is predominantly based on cultural and social factors. The variety of links, cooperation, mutual trust, and communication among the members of a network will fulfill the goals of the members. In addition, social capital for development programs is a success factor. The existence of social capital is a suitable platform for economic and physical capital productivity. Home nurses are seeking social capital as a social actioner. Social capital is considered as a source for facilitating collective action. And this source includes trust, norms, or mutual behaviors (partnerships) in addition to paying attention to social affairs. Nurses seek to create a space of trust that can work reliably. They believe that by controlling the environment, creating conditions for understanding, consoling and showing reassuring behavior will be important. It is through trust, that a nurse actually creates a space of trust and support.

\subsubsection{Professional interaction}

The main idea of social capital is that communication and interactions constitute a very important asset, and one person can use them in a critical condition. Home nurses use professional interaction and communication as a supportive resource. A home nurse says: "Experienced colleagues are good advisers for me. Especially in the first 
six months of my experience, I was faced with a lot of problems, but after a year, the situation gradually became better. At the same time, there are still some cases that I need to consult, especially in cases that I have not experienced. A good colleague in this situation can remind me of things that I did not think of at all." (p.7). They also consider sharing their experiences as a factor in becoming professional: "If I am asked for my opinion, I am ready to help, if I can. Because it is serious for me, I would love to develop home care nursing ... I would love to see this progress." From nurses' points of view, another professional strategy is to encourage home nurses to socialize through groups and associations to reach the voice of the group from nurses to the public and the authorities. A partner with 12 years of home care experience says: "Employees working in this setting should also have a trade union organization that will address them to the Ministry of Health, so they can defend their rights in the future. Even such an association in the training of new colleagues can also be effective." (p.11)

\subsubsection{Social position}

The dignity and authority of the nurse is due to the position of dignity in a social system. Nurses' social status is an assessment based on valid social value criteria in the community, from the position of a nurse in the minds of others, and shows how the nurse's position is relative to the position of other people in the "social space". In fact, nursing dignity is a value that society attaches to the role of the nurse. Home nurses are worried about their dignity in the community in Iran. A home nurse says: "It was a time when I was at home and he had a few visitors. I did not feel well at all. I was unhappy because a home nurse is considered a home worker in Iranian society. I felt humiliated .... I do not think home nursing is recognized in Iran, like so many other things." (p.5)

\subsection{Maintaining quality and standards of care}

In terms of participants, quality of care is a range of services provided to individuals who increase the probability of appropriate results, and the nurses have the necessary information, skills, capabilities and updated professional knowledge. Participants consider the existence of professional standards and monitoring of them as a means to improve quality. For nurses, standard care is a critical part of home care, and plays an important role in determining quality care concepts.

\subsubsection{Monitoring and accreditation:}

Participants believed that success in providing optimal nursing services at home depends on an effective assessment of the quality of services provided. "I think the supervisory team can do something. They can communicate with the family that they have been giving nursing care to. The family is the best supervisor. This is a law, the best supervisor is the service recipient ....... you are the director of the center. And you want to supervise the nurse who was sent to the patient's home. Now with cell phones and telegrams ... it can do a lot ... You can immediately contact the family. Are you satisfied with the service? How much did he get? Did you give her a gift? Do you have a complaint with her? All of these questions can be asked. That's where they offer a good service, they do it .... That means customer management." (p.4). "How good it will be to monitor any unnecessary action. Supervision is equal to maintaining a supreme position of nursing. Every nurse does his / her job and does not do other tasks. Supervision should be given to unauthorized persons and institutions...... and we have to understand that lack of competence does not mean the lack of a degree...... and it's much better to have a platform for accreditation centers in the future. Because at the time of obtaining the license, only the minimum is taken into account "(p.21)

\subsubsection{Attention to the authority of knowledge and experience}

Participating nurses emphasized the need to take advantage of the updated science, along with clinical experiences in care. According to them, nurses should have high academic knowledge and skills. A nurse with 20 years of work experience says: "It means that it is safe to say that the home is not the place to carry out techniques for the first time. You should even know how to use leucoplast as a professional. Unlike hospital nursing ... But at home, you have to have enough skill in every technique. When a nurse has enough information and science to come home, he will be more confident, surely. I think that you need to have a lot of information to work at home. The patient's family puts a packet of medicine in front of us and tells us how our patient should take them. This is when you should have good pharmacological information..." (p.2). Many of them referred to the need for specific home care education courses, and they agree with it. A nurse with 15 years of work experience at home: "The only difficulty is that we are far from new nursing science ... Indeed, if this information is available, I would be very happy to know it ... Creating a home-based nursing retraining course is a solution to keeping their information up to date." (p.8). At the same time, they do not consider the skills and knowledge aspects to be discounted from clinical experience, and nurses consider it necessary to have previous clinical experience before entering home care. A nurse with 5 years of work experience at home says: "I myself entered this profession without experience, but I do not advise that low experienced nurses enter this practice. You should have a few years of experience in the hospital, because you need an adequate base of experience .... First of all you should have some skills. Because you are an independent worker, you need to know that if an emergency arises, what you should do about it." (p.7) 


\subsubsection{Specialization}

Participants in this study believed that they needed to be specialized in providing professional and quality care. A participant with 4 years of home care experience says: " A nurse experienced in wound dressing has three qualities: she knows wounds very well, performs a good assessment, and chooses a good dress. If you're using this routine dressing for every wound, that it does not need to me anymore. A associated nurse can also put this dressing on the wound, so I'm an expert. We try not only to cover the wounds.... My nurse is trained, he especially knows about wounds. The benefits of this are that we can claim that we do special care for wound healing. It would have been better if specialized institutions were working. For example, an institute would provide a wound care services and the other for phototherapy and another chemotherapy center" (p.10). Another nurse with 15 years of work experience in home care and entrepreneurship with academic education: "Nursing institutions need to be more specialized in order to both make money and improve the quality of services. Today, some institutions are looking for wound dressings. One is in the field of counseling, another in the field of phototherapy and ... more specialized. If they limit their field of work, they can become a better brand in the professional field." (p.5). Some participants have stated that they are trying to avoid entering areas where they do not have enough expertise. "We usually do not accept babies because they do not have specialist nurses for the specific care needed." (p.11).

\subsubsection{Clinical Competency}

Clinical competency is another subcategory of "Maintaining quality and standards of care" that the participants refer to. They considered determining the level of nurses' proficiency and effectiveness in preventing professional errors, ethical and legal violations. A nurse with 5 years of work experience in home care said: "However, it will take a long time to become a good nurse in home care. This requires excellent skill. This requires the power of thought and decision. First of all, I have one thing to say and that is - a good nurse in home care needs humility. You must be patient. If you expect everything to be planned because in its own direction, you will fail."(p.7). "A home nurse is a professional who has a high level of clinical skills in addition to having credible qualifications and high level academic knowledge, and he personally has several important indicators, such as high self-esteem, ability to manage in a crisis, ability to communicate effectively, the ability to provide education to different classes of society." "In home care, in addition to having enough knowledge and experience, we can point to indicators such as familiarity to teamwork and professional relationships, sociology and culture, public relations, and labor laws, creativity of innovation and .... Given that there is a limitation to the means and professionals in home care, mastery of work and having the ability of critical management is mandatory. Having reasonable self-confidence is necessary because we deal with multiple people at different levels of information at home".

\subsubsection{Effective management}

Participants also stated that effective supervising and control on how to provide services at home by institutional managers is an important indicator of maintaining quality in home care. In their view, managers should ensure the effectiveness of the care provided. "When we send a nurse to the patient's home, we are always in touch with the family, ..... We ask about the process of work and family satisfaction. We will check the nurse frequently ....... However, families in the home feel freer to intervene in nursing, but we try to control this situation." Effective managers also lead the staff and care program towards a high quality. "First, the patient or elder is evaluated by the director or supervisor. Based on the assessment, the type of work is determined, the drugs are identified by the manager or supervisor, and the time is determined according to the list, and announced to the personnel."

\section{Discussion}

The main purpose of the present study was to explain the professionalism of nurses' attitudes that were expressed in nurses' experiences in home care. Indeed, these themes are the answer to the question of what the factors and dimensions of professional care are, in home care. Overall, the results of the coding and categorization of obtained data in this study showed that the concept of professionalism in home care includes focusing on basic values, social capital, and maintaining quality and standards of care. In this study, most home nurses considered their work worthwhile. They believed that every professional nurse should respect social values of the community. A nurse should be responsive to providing competent home care and try to achieve professional and legal standards in conducting his or her performance. How do nurses become trustworthy? How much do they do to their obligations? How much do people trust the performance of home nurses? The answer to these questions is related to the foundation of value by nurses. Heydari and colleagues point to the cultural dimensions of values and beliefs as one of the most effective elements of home care (10). Holm believes that ethical codes help maintain the integrity of professional and individual values, and for nurses who cannot balance values with services, the result will be the inappropriate care of the patient (15). The results of the studies mentioned above are consistent with the present study. Nurses were required to comply with legal frameworks in this study. Safe nursing practices require understanding the legal framework that each nurse should take. Nikomanzari says that nurses should pay attention to 
this because their decisions and actions should be based on legal, ethical and professional principles (16). For this reason, legalism is one of the professional aspects of home care nursing. The concept of social capital was one of the main findings of this research. Social capital is a complex, multifaceted, and interdisciplinary concept attracting the attention of many nursing experts. Lauder and Looman have considered social capital to be unique, and believe that social capital is a way for nurses to engage in social interactions and create meaning and public trust related to health $(17,18)$.

One of the most important findings of this research was attention to maintaining quality and standards of care, which itself has dimensions and factors such as monitoring and accreditation, attention to the authority of knowledge and experience, clinical competence, effective management and specialization. The health system in the country needs to be sure of the professional competence of home nurses. It is essential that the skills are carefully measured, evaluated and judged. Although professionalism, skills and abilities in nursing care have been criticized many times (19), this problem seems to remain. Based on the results of this study, lack of clinical knowledge and experience was a factor in the failure to perform professional care. The experiences of the participants in this study showed that nursing graduates not only lack in knowledge and skills to accept their new role as independent nurses at home, but also have weaknesses in self-confidence and the ability to make the right decision as one of the essential nursing skills. The most important problems in the experiences of participants in this study were the need for further study, weakness in clinical skills, and the inability to make accurate and timely decisions in critical situations such as dealing with dying patients, which are consistent with the results of other studies. The findings of an Abedi et al. research on nurses' objective experiences, also showed that many nurses were incapable of entering the work environment in some cases (20). Heydari and colleagues also refer to the lack of specialized knowledge as one of the problems of nursing at home, and one of the main obstacles in providing quality care in home care is the lack of qualified personnel $(10,21)$. Norris says that a novice nurse may be expected to work like an expert nurse. These issues will enable a novice nurse to adapt to the conditions appropriately as a result of existing conflicts between expectations and workplace realities. As a result, there are adverse reactions in physical and psychological aspects, such as disability, depression, insecurity due to lack of efficiency in the workplace, and ultimately, withdrawal from nursing care (22). According to the American Nursing Association, graduates should be prepared to perform their duties in light of the rapid changes in the health system and the market (23). Efforts to improve knowledge in these issues can be a factor in increasing professionalism. It seems that a nurse's clinical knowledge and skills give her more strength to do home care and promote social position. The results of this study also point to the need for specialized care. The importance of specialized nursing work is identified in unexpected clinical problems. It is evident that a number of nurses are not able to provide high-quality services in all cases, due to the wide range of nursing home cares. Therefore, specialized nursing services at home is a must. The result of this specialization will be the establishment of credentials, career standards and general ethical principles. Home nurses also call for comprehensive efforts in qualifications, legality, competence, ethics, financial backing, and service provision. Management skills and professional relationships were also highlighted as other indicators of professionalism, which, of course, were shared with other scholars (24). Apker and colleagues confirmed that interdisciplinary communication is essential for the professional team and the effective communication of the team (25). Nursing managers' dominance of management principles, the precise use of managerial skills, the creation of a sense of trust and commitment to the institution, and the engagement of nurses are the tools that help to create a suitable environment for work and achievement of goals. In fact, increasing productivity is a sign of good organization and management for the advancement of care (26). The variety and wide range of home nursing care and the lack of access to all nurses working in this area were the limitations of this study. It is suggested that exploration in the experiences and perceptions of nurses and other caregivers from the care professionals at home, including nurses or those who are unlicensed, with different specializations is carried out in later studies.

\section{Conclusions}

Although the move towards professionalism in home care has started in Iran, there is still a long way to go. Participants expressed their experiences in this study in three areas: Attention to basic values, social capital, maintaining quality and standards of care. The results showed that nursing professionalism at home is influenced by various confounding and facilitating factors, so that having individual and professional abilities, such as theoretical knowledge and practical skills, work experience, condition management, communication skills, ethical commitment, and professional, personal and social values are facilitators. Failure of the management and education system, as well as the negative attitude of the community, and social dysfunctions were identified as barriers to professionalization in home care. The barriers that have been roughly emphasized by other research have also caused the nurses to feel less confident and professional in their profession. Since the findings from qualitative 
studies lead to the understanding of a phenomenon in a particular situation, the findings of this study cannot be generalized to other situations and will be limited in scope. Nevertheless, these studies create insights that help guide nursing activities and planning, and help the process of theorizing.

\section{Acknowledgments:}

This article was written as part of the Ph.D. in Nursing, which was registered at Mashhad University of Medical Sciences at No. 941375 and sponsored by the Deputy of Research and Technology of Mashhad University of Medical Sciences. The researchers would like to express their thanks for the cooperation of Mr. Ezzati, Managing Director of Nursing at Mashhad University of Medical Sciences, Mr. Bakhtiari, Mrs. Gheibi and all the participating nurses involved, who helped us in this study.

\section{Conflict of Interest:}

There is no conflict of interest to be declared.

Authors' contributions:

All authors contributed to this project and article equally. All authors read and approved the final manuscript.

\section{References:}

1) Tabatabai A, Abbaszadeh A, Mohammadnejhad E. Nursing and professionalism: perception of cardiac care unit nurses. J Qual Res Health Sci. 2015; 4(1): 86-96.

2) Adib Haj Bagheri M, Salsali M, Ahmadi F. The concept of professional power in nursing. FEYZ. 2004; 8(1): 9-19.

3) van Mook WN, de Grave WS, van Luijk SJ, O'Sullivan H, Wass V, Schuwirth LW, et al. Training and learning professionalism in the medical school curriculum: current considerations. Eur J Intern Med. 2009; 20(4): 96-100. doi: 10.1016/j.ejim.2008.12.006. PMID: 19524167.

4) Shinyashiki GT, Mendes IAC, Trevizan MA, Day RA. Professional socialization: students becoming nurses. Revista latino-americana de enfermagem. 2006; 14(4): 601-7. doi: 10.1590/S010411692006000400019. PMID: 16967168.

5) Nakrem S, Vinsnes AG, Seim A. Residents' experiences of interpersonal factors in nursing home care: a qualitative study. International journal of nursing studies. 2011; 48(11): 1357-66. doi: 10.1016/j.ijnurstu.2011.05.012. PMID: 21696735.

6) Carlson E, Bengtsson $M$. The uniqueness of elderly care: registered nurses' experience as preceptors during clinical practice in nursing homes and home-based care. Nurse education today. 2014; 34(4): 569-73. doi: 10.1016/j.nedt.2013.07.017. PMID: 23954003.

7) Genet N, Boerma WG, Kringos DS, Bouman A, Francke AL, Fagerström C, et al. Home care in Europe: a systematic literature review. BMC health services research. 2011; 11(1): 207. doi: 10.1186/1472-6963-11207. PMID: 21878111, PMCID: PMC3170599.

8) Or CK, Valdez RS, Casper GR, Carayon P, Burke LJ, Brennan PF, et al. Human factors and ergonomics in home care: Current concerns and future considerations for health information technology. Work. 2009; 33(2): 201-9.

9) Carlson E, Ra“mga ${ }^{\circ}$ rd M, Bolmsjo I, Bengtsson M. Registered nurses’ perceptions of their professional work in nursing homes and home-based care: A focus group study. Int J Nurs Stud. 2014; 51: 761-7. doi: 10.1016/j.ijnurstu.2013.10.002. PMID: 24176717.

10) Heydari H, Shahsavari H, Hazini A, Nasrabadi AN. Exploring the Barriers of Home Care Services in Iran: A Qualitative Study. Scientifica. 2016; 2016.

11) Azemian A. The standards of professionalism in nursing: the nursing instructors' experiences. Evidence Based Care. 2014; 4(1): 27-40.

12) Graneheim U, Lundman B. Qualitative content analysis in nursing research: concepts, procedures and measures to achieve trustworthiness. Nurse Education Today. 2004(24): 105-12. doi: 10.1016/j.nedt.2003.10.001. PMID: 14769454.

13) Guba EG, Lincoln YS. Competing paradigms in qualitative research. Handbook of qualitative research. 1994; 2(163-194): 105.

14) Goethals S, Gastmans C, de Casterlé BD. Nurses' ethical reasoning and behaviour: a literature review. Int J Nurs Stud. 2010; 47(5): 635-50. doi: 10.1016/j.ijnurstu.2009.12.010. PMID: 20096413.

15) Holm S. What should other healthcare professions learn from nursing ethics. Nursing Philosophy. 2006; 7(3): 165-74. doi: 10.1111/j.1466-769X.2006.00280.x. PMID: 16774603. 
16) Nikomanzari A, Afsharnia F, Joulaee S, Hajibabaee F. Nursing care negligence in Iranian Judiciary. Quarterly Journal of Nursing Management. 2015; 4(2): 9-18.

17) Lauder W, Reel S, Farmer J, Griggs H. Social capital, rural nursing and rural nursing theory. Nursing inquiry. 2006; 13(1): 73-9. doi: 10.1111/j.1440-1800.2006.00297.x. PMID: 16494669.

18) Looman WS. Defining social capital for nursing: Experiences of family caregivers of children with chronic conditions. Journal of Family Nursing. 2004; 10(4): 412-28. doi: 10.1177/1074840704269846.

19) Borhan F, Alhani F, Mohmadi E, Abasszadeh A. Develop to Nursesing Qualified Professional Ethics, Needs and Challenges in Ethics Education. J Med Ethics Hist Med. 2009; 2(2): 27-38.

20) Abedi HA, Heidari A, Salsali M. New graduate nurses' experiences of their professional readiness during transition to professional roles. Iranian Journal of Medical Education. 2004; 4(2): 69-78.

21) Heydari H, Rahnavard Z, Ghaffari F. Exploring the Position of Community-Based Nursing in Iran: A Qualitative Study. Int J Community Based Nurs Midwifery. 2017; 5(4): 386-96. PMID: 29043284, PMCID: PMC5635558.

22) Norris T. Making the transition from student to professional nurse. Contemporary nursing St Louis: Mosby Co; 2002.

23) Davis AH, Kimble LP. The essentials of baccalaureate education for professional nursing practice. Journal of Nursing Education, 2011 - m3.healio.com

24) Vaughan BA. Newly qualified staff nurse: factors affecting transition: University of Manchester; 1980.

25) Apker J, Propp KM, Ford WSZ, Hofmeister N. Collaboration, credibility, compassion, and coordination: professional nurse communication skill sets in health care team interactions. Journal of Professional Nursing. 2006; 22(3): 180-9. doi: 10.1016/j.profnurs.2006.03.002. PMID: 16759961.

26) Vafaee Najar A, Habashizade A, Karimi H, Ebrahimzade S. The effect of improvement of nursing managers' professional competencies based on performance on their productivity: An interventional study. Daneshvar. 2011; 18(94): 63-72. 